\title{
Singapore Advanced Cardiac Life Support Guidelines 2021
}

Chi Keong Ching ${ }^{1}$, MBBS, MRCP, Benjamin Sieu-Hon Leong ${ }^{2}$, MBBS, MRCSEd, Praseetha Nair ${ }^{3}$, MBBS, MMed, Kim Chai $\mathrm{Chan}^{3}$, MBBS, FRCSEd (A\&E), Eillyne Seow ${ }^{3}$, MBBS, FRCSEd (A\&E), Francis Lee ${ }^{3}$, MBBS, FRCSEd (A\&E), Kenneth Heng $^{4}$, FRCS (A\&E), MHPEd, Duu Wen Sewa ${ }^{5}$, MBBS, MRCP, Toon Wei Lim ${ }^{6}$, MBBS, PhD, Daniel Thuan Tee Chong ${ }^{1}$, MBBS, MRCP, Khung Keong $\underline{\text { Yeo }^{1}}$, MBBS, Wee Kim Fong ${ }^{7},{ }_{\text {MBBS, }}$ MMed (Anaes), Venkataraman Anantharaman ${ }^{8}$, MBBS, FRCPEd, Swee Han $\underline{\mathrm{Lim}}^{8}$, FRCSEd (A\&E), FRCPEd

\begin{abstract}
Advanced cardiac life support (ACLS) emphasises the use of advanced airway management and ventilation, circulatory support and the appropriate use of drugs in resuscitation, as well as the identification of reversible causes of cardiac arrest. Extracorporeal cardiopulmonary resuscitation and organ donation, as well as special circumstances including drowning, pulmonary embolism and pregnancy are addressed. Resuscitation does not end with ACLS but must continue in post-resuscitation care. ACLS also covers the recognition and management of unstable pre-arrest tachy- and bradydysrhythmias that may deteriorate further.
\end{abstract}

Keywords: advanced cardiac life support (ACLS), arrhythmias, defibrillation, resuscitation

\section{INTRODUCTION}

Advanced cardiac life support (ACLS) is the fourth link in the 'chain of survival'. Its success hinges on the optimal conduct of the previous three links: early access, early cardiopulmonary resuscitation (CPR) and early defibrillation. ACLS guidelines provide succinct arrhythmia management principles, interventions to optimise return of spontaneous circulation (ROSC) and evidence-based post-resuscitation interventions to enhance the chances of being discharged alive from the hospital with favourable neurological outcomes. The 2021 ACLS guidelines address the key components of this vital link and provide an update of the earlier guidelines that were published in 2017.(1)

\section{CARDIAC ARREST: EARLY RECOGNITION AND CALL FOR HELP}

Cardiac arrest may occur outside or inside the hospital, termed out-of-hospital cardiac arrest (OHCA) or in-hospital cardiac arrest (IHCA), respectively. For OHCA, the emphasis is on early recognition by the public and access to emergency prehospital care, while close monitoring and early warning systems enable timely recognition of IHCA.

\section{OUT-OF-HOSPITAL CARDIAC ARREST AND PREHOSPITAL RESPONSE}

Over the years, Singapore has made continuous improvements in the community, emergency medical services (EMS), hospitals and the integration in the chain of survival. ${ }^{(2)}$ Prehospital emergency medical systems should provide telephone instructions for CPR; (3) activate community first responders; and rapidly dispatch basic cardiac life support (BCLS) and EMS first responders trained in the use of automatic external defibrillators (AEDs), high-performance
CPR teams ${ }^{(4)}$ and paramedics to the scene as soon as possible (preferably within eight minutes). ${ }^{(5)}$ Optimisation of EMS asset deployment and stratified levels of responses for calls of different priority levels are important to ensure timely arrival. EMS interventions and protocols need to be regularly reviewed according to evidence. Transport to specialised cardiac arrest centres may also improve outcomes. ${ }^{(6)}$

\section{IN-HOSPITAL CARDIAC ARREST}

Hospitalised patients have a higher risk of deterioration that may progress to unrecognised cardiorespiratory arrest. ${ }^{(7)}$ In addition, patients in cardiac arrest may be brought to or happen to be in public areas of the healthcare facilities. All staff from healthcare facilities should be educated to immediately recognise cardiac arrest and activate the emergency response system. Nonclinical staff are encouraged to be BCLS- and AED-certified, like any member of the public. All clinical staff are also be expected to be BCLS- and AED-certified, unless excused for health reasons. Hospitals should adopt a universal system to activate a team of currently certified BCLS- and ACLS-trained medical staff to be on standby for all clinical and public locations. Equipment required for resuscitation should be standardised and conveniently placed for rapid access. Hospitals should review cardiac arrest events regularly to identify opportunities for systems improvement and disseminate key learning points to all staff.

\section{ROLE OF RAPID RESPONSE TEAMS}

Patients may show symptoms of deterioration for hours to days before cardiopulmonary arrest. This provides a window of opportunity for hospital teams to intervene early and potentially change patient outcomes. Medical emergency teams, ${ }^{(8)}$ rapid

\footnotetext{
${ }^{1}$ Department of Cardiology, National Heart Centre Singapore, ${ }^{2}$ Emergency Medicine Department, National University Hospital, ${ }^{3}$ Acute and Emergency Care Centre, Khoo Teck Puat Hospital, ${ }^{4}$ Emergency Medicine Department, Tan Tock Seng Hospital, ${ }^{5}$ Department of Respiratory Medicine, Singapore General Hospital, ${ }^{6}$ Department of Cardiology, National University Hospital, 'Department of Anaesthesia, Tan Tock Seng Hospital, ${ }^{8}$ Department of Emergency Medicine, Singapore General Hospital, Singapore

Correspondence: A/Prof Ching Chi Keong, Senior Consultant, Department of Cardiology, National Heart Centre Singapore, 5 Hospital Drive, Singapore 169609. Ching.chi.keong@singhealth.com.sg
} 
response teams (RRT), ${ }^{(9)}$ cardiac arrest teams $^{(10)}$ or code blue teams ${ }^{(11)}$ help to reduce unexpected IHCA. The Institute for Healthcare Improvement recommends hospital-wide systems that allow observation, detection of deterioration and tailored response to ward patients. ${ }^{(12)}$ RRTs could have a role to facilitate shared decisionmaking and advanced care planning (including resuscitation decisions) for patients with significant comorbidities and limited quality of life. ${ }^{(13)}$ These plans should be consistently recorded and handed over between teams using structured communication tools.

\section{UNIVERSAL ALGORITHM FOR CARDIAC ARREST}

The management of cardiac arrest is time critical, and standardised algorithms guiding key interventions have been a key feature in ACLS. The 2021 updated universal algorithm is depicted in Fig. 1.

\section{Primary survey}

The primary survey emphasises early recognition of cardiac arrest, rapid initiation of CPR and early defibrillation. Upon recognition or discovery of a 'critically ill patient', ensure that there is no danger before proceeding. Check for responsiveness; if the patient is unresponsive, shout for help and activate the emergency response system. Obtain a defibrillator as soon as possible. Assess the patient for breathing and a pulse.

\section{Chest compressions}

Regardless of the setting of the cardiac arrest, good-quality chest compressions must be initiated without delay. While the time to arrival of resuscitation teams and initiation of CPR is important, more needs to be done to emphasise the quality of the resuscitation. The measures of chest compression quality in adults are detailed in the article on $\mathrm{BCLS}^{(14)}$ and are summarised as follows: compression depth of 4-6 cm, rate of 100-120 per minute, complete chest recoil and interruptions of less than ten seconds.

Real-time CPR feedback systems and devices, used as part of a comprehensive training, response and quality framework, are recommended to improve the quality of CPR. ${ }^{(15)}$ While automated mechanical CPR devices have not been found to be superior to manual chest compressions in terms of survival or neurological outcomes, ${ }^{(16)}$ they may be useful in clinical situations that do not permit high-quality manual CPR, such as in a moving ambulance, during the transfer of a patient, or in case of arrest during cardiac catheterisation. Prompt application has been associated with improved outcomes, ${ }^{(17)}$ and training is important to reduce the time required to deploy these devices. ${ }^{(18)}$

\section{Ventilations during $C P R$}

In an OHCA, where the bystander is untrained and provided with dispatcher-assisted CPR instructions over the phone, ventilations may be omitted. In cases where a trained rescuer is available, or in paediatric cardiac arrests, ventilations are recommended at the standard compression-to-ventilation ratio of 30:2. In the context of widespread communicable diseases, ventilations should be provided using a bag-valve-mask (BVM) device instead of mouth-to-mouth.
In IHCAs or where BVMs are available, ventilations should be delivered together with continuous chest compressions (CCCs). The airway is first opened and airway adjuncts are inserted, as necessary. The mask size is estimated using the distance between the bridge of the nose to the chin. The mask is held using one hand with the 'EC' configuration (Fig. 2). The thumb and the index finger (' $\mathrm{C}^{\prime}$ ) hold the mask onto the face, while the middle, ring and little fingers (' $\mathrm{E}$ ') lift the body and angle of the mandible. The other hand performs bag ventilation. In the case of two rescuers taking care of ventilations, one rescuer may use both hands to hold the mask while the other performs the bagging. Ventilations are provided at ten breaths per minute, and about 400-600 mL per breath, which is equivalent to about one-third of the bag, sufficient to cause the chest to rise. Care must be taken to avoid squeezing the entire volume of the bag with each breath. Excessive ventilations, either in rate or volume, confer no benefit, as the pulmonary circulation achieved with CPR during cardiac arrest is poor and will not absorb more oxygen. In fact, excessive ventilations may be harmful owing to the raised intrathoracic pressures impeding venous return to the heart, as well as risks of gastric insufflation and consequent regurgitation and aspiration.

\section{Cardiac arrest rhythms}

There are four possible electrical rhythms in cardiac arrest: ventricular fibrillation (VF), pulseless ventricular tachycardia $(\mathrm{pVT})$, pulseless electrical activity (PEA) and asystole. VF and pVT are shockable rhythms, which should be treated by defibrillation, while PEA and asystole are non-shockable rhythms, which should not be defibrillated. VF is a disorganised electrical rhythm caused by rapid uncontrolled depolarisation and contraction of the ventricular myocardium, resulting in loss of normal effective pumping action of the ventricles. Refractory VF is VF that has failed to respond after being shocked three or more times. Recurrent VF is VF that had been initially terminated by a shock but recurred later. Ventricular tachycardia (VT) is a dysrhythmia caused by rapid abnormal contraction of the ventricles, and may be stable, unstable or pulseless. When VT is pulseless (pVT), it should be treated similar to VF with defibrillation shocks. PEA is a state of organised electrical activity on electrocardiogram (ECG; Fig. 3), excluding VT, without a palpable pulse. PEA may occur as the initial rhythm in cardiac arrest or as an intervening rhythm associated with treatment of cardiac arrest. Asystole (Fig. 4), commonly called 'flat line' on ECGs, is a state of cardiac standstill without ventricular depolarisation. In primary cardiac arrest, this is often due to depletion of myocardial energy stores. It is an indicator of grave cardiac prognosis and often responds poorly to treatment; it is the final rhythm in all dying patients. Fine VF may be mistaken as asystole. If manual rhythm analysis is performed, the size of the rhythm tracing should be increased to improve recognition of fine VF.

\section{Defibrillation}

\section{Defibrillator pad placement}

On arrival of the cardiac monitor/defibrillator or AED, apply the self-adhesive defibrillation pads on the exposed chest 


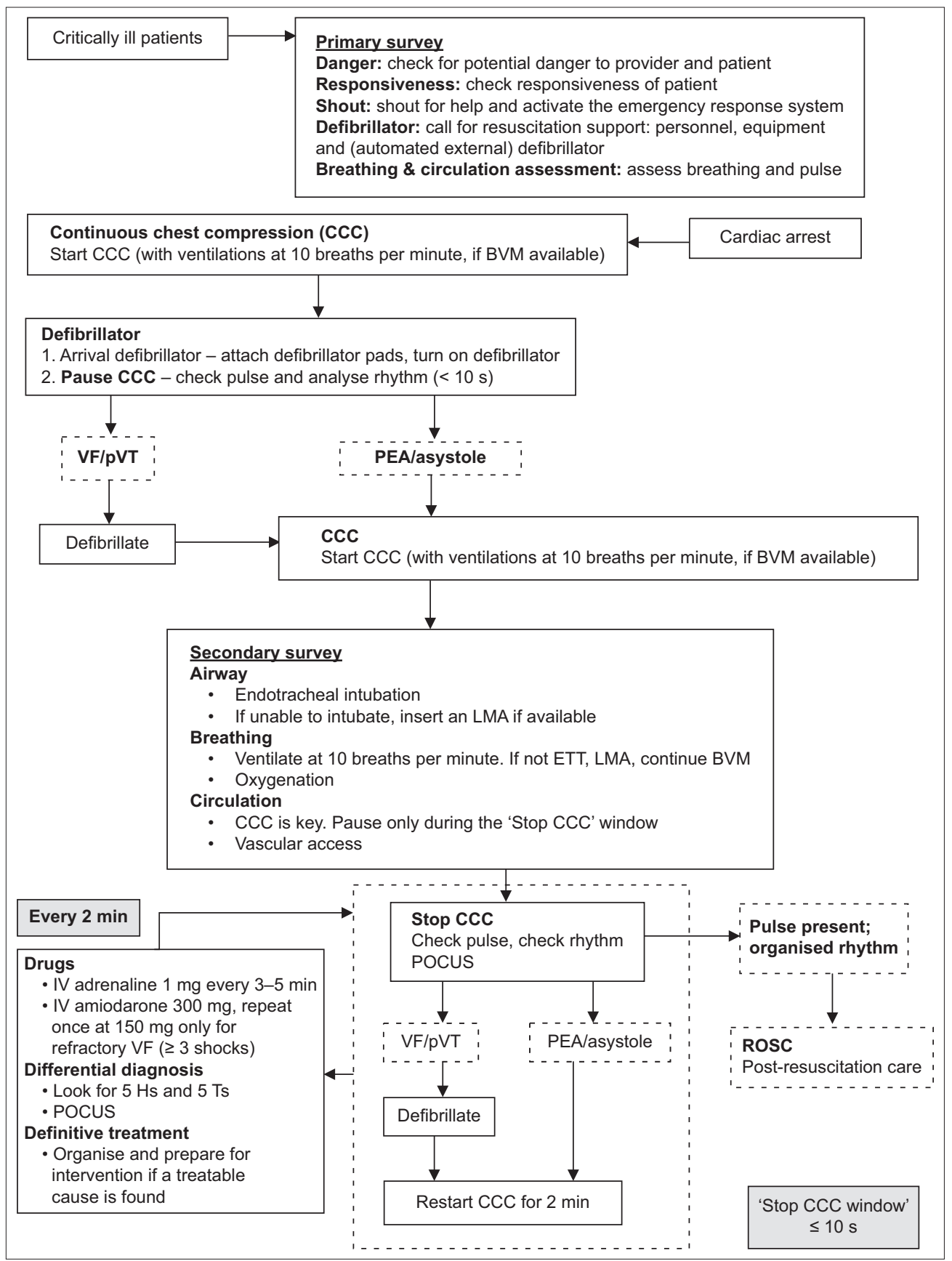

Fig. 1 Flowchart shows the 2021 updated universal algorithm for cardiac arrest. BVM: bag-valve-mask; ETT: endotracheal tube; IV: intravenous; LMA: laryngeal mask airway; PEA: pulseless electrical activity; POCUS: point-of-care ultrasonography; PVT: pulseless ventricular tachycardia; ROSC: return of spontaneous circulation; VF: ventricular fibrillation

immediately, without interrupting CPR. These may be used for both rhythm analysis and delivery of shocks. Remember to switch the cardiac monitor-defibrillator to paddle/pads mode. Do not waste time applying the ECG leads first, as these cannot be used to deliver shocks. Defibrillation pads may be placed in an anterior-lateral (A-A) or anterior-posterior position (A-P); there is currently no clear evidence regarding the superiority of either approach with biphasic defibrillation. ${ }^{(19)}$

Manual vs. automated rhythm analysis

The key aim of rhythm analysis in cardiac arrest is to identify a shockable rhythm. Contemporary AEDs are highly accurate in their detection of shockable rhythms, but these algorithms necessitate a significant pause in CPR for analysis. Hence, if an operator skilled in rapid rhythm analysis is present, operating the defibrillator in manual mode would help reduce the hands-off time. ${ }^{(20)}$

\section{Defibrillation waveforms}

Both monophasic and biphasic defibrillators are recommended for defibrillation in VF or $\mathrm{pVT}$, as well as electrical cardioversion of haemodynamically unstable supraventricular or atrial tachyarrhythmias. While neither waveform has been shown to be superior to the other, biphasic defibrillation is favoured as it results in a lower peak electrical current while achieving similar or greater efficacy. ${ }^{(21)}$ 

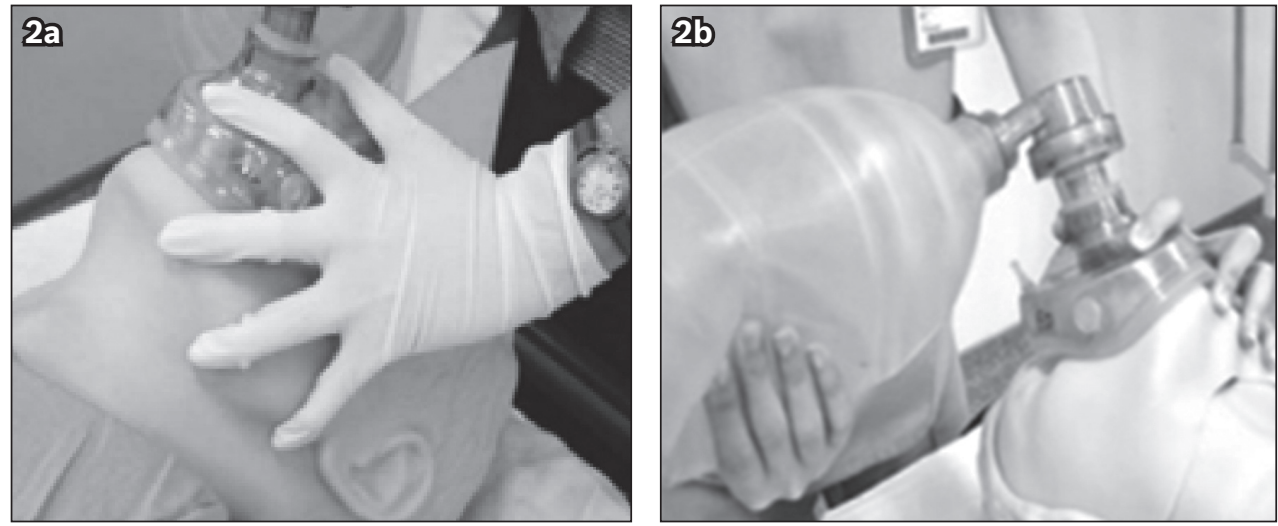

Fig. 2 Photographs show the use of bag-valve-mask. The airway is first opened and airway adjuncts are inserted, as necessary. (a) The mask size is estimated using the distance between the bridge of the nose and the chin. (b) The mask is held using one hand with the 'EC' configuration.

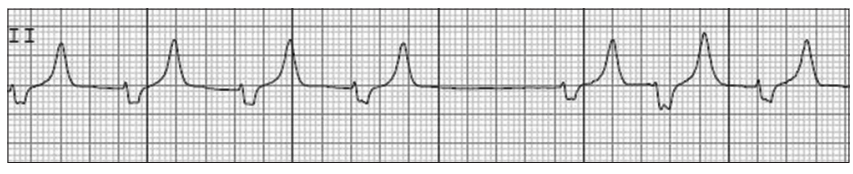

Fig. 3 ECG shows pulseless electrical activity due to hyperkalaemia.

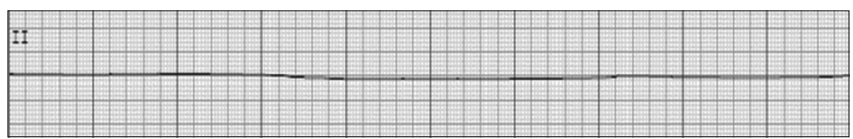

Fig. 4 ECG shows asystole.

\section{Shock strategy and starting energy}

A single shock strategy is preferred to 'stacked' shocks, as it affords minimal interruption to CPR and has been shown to improve survival to hospital admission and discharge. ${ }^{(22)}$ There is no clear evidence for an optimal initial shock energy level. The minimum shock energy level may be as low as $120 \mathrm{~J}$ for devices using rectilinear biphasic waveforms and $150 \mathrm{~J}$ for devices using biphasic truncated exponential waveforms. As commercially available defibrillators have different energy settings and waveforms, it is reasonable to follow the manufacturers' recommendations. In case of doubt, it is reasonable to start at $150 \mathrm{~J}$ for biphasic defibrillators and $360 \mathrm{~J}$ for monophasic defibrillators and escalate the energy for subsequent shocks. ${ }^{(23)}$ Alternatively, defibrillation at the maximum energy setting may also be considered.

\section{Double sequential defibrillation}

Double sequential defibrillation is a popular method of applying two sets of defibrillators on the patient for treatment of refractory VF and discharging both defibrillators simultaneously or in quick succession. This has not been found to be more effective than standard defibrillation strategies and is not recommended. ${ }^{(24)}$

\section{CPR and defibrillation}

$\mathrm{CPR}$ is critical to maintain coronary and cerebral perfusion during cardiac arrest and should be started without delay and continued until a defibrillator is available. However, once the defibrillator is available, there is no advantage of instituting prolonged periods of
CPR prior to initial defibrillation. This applies even if the rhythm appears to be fine VF. There is no need to 'coarsen the VF' with prolonged CPR prior to the initial shock. Hence, upon arrival of the defibrillator, the rhythm should be immediately analysed and defibrillation should be performed once the defibrillator is charged. ${ }^{(25)}$ In the case of a witnessed arrest, it is also reasonable to deliver a shock prior to CPR if defibrillation is immediately available, as early defibrillation improves outcomes. ${ }^{(26)}$ Thereafter, once the initial shock has been delivered, CPR should be resumed immediately until the end of the next rhythm analysis, which may be 1-2 minutes later.

\section{Peri-shock pauses}

Pauses in CPR before and after defibrillation, called peri-shock pauses, have been associated with poorer outcomes if they last longer than $5-10$ seconds. ${ }^{(27)}$ Once a shockable rhythm is recognised, whether by AED analysis or by manual analysis, chest compressions should be continued during charging of the defibrillator, until just before the shock is delivered. Although it is vital to ensure that the scene is 'clear' for safety, CPR should have minimal interruptions. Resuscitation teams should practise clearing chants (e.g. 'shocking on 3-2-1') that incorporate careful coordination between the operator delivering the shock and the rescuer performing chest compressions, to stop CPR, shock and restart CPR immediately.

\section{Stop CCC window}

After every 1-2 minutes, CCC may be stopped to check the pulse and the rhythm. Point-of-care ultrasonography (POCUS) may be performed to look for treatable causes of cardiac arrest. If a shockable rhythm is present, perform defibrillation and restart CCC immediately. If there is a non-shockable rhythm with no pulse, restart CCC immediately. If a pulse is present, ROSC has occurred; proceed to post-resuscitation care. The 'stop CCC window' should not take more than ten seconds.

\section{Secondary survey}

During the secondary survey, advanced interventions including airway management, oxygenation and ventilation, and vascular access are performed, and drugs are administered. 


\section{Airway management}

A patent airway, adequate ventilation and oxygen supplementation are important to ensure continued oxygenation and ventilation, and should be established within a few minutes of the start of resuscitation.

No high-quality evidence exists favouring one technique over another to establish and maintain a patent airway, and multiple approaches may be required. Rescuers should be aware of and proficient in the various techniques. Techniques to open the airway with the head-tilt, chin-lift manoeuvre, modified jaw thrust, removal of foreign bodies and delivery of rescue breathing are described in the section on BCLS. This section will focus on delivery of ventilation in medical facilities.

\section{Airway adjuncts}

Airway adjuncts are designed to be inserted through the oral or nasal air passages to prevent occlusion of the upper airway and assist in maintaining airway patency.

Oropharyngeal airway, also known as the 'Guedel' airway (Fig. 5), interposes between the tongue anteriorly and the back of the pharynx posteriorly, preventing the tongue from falling backwards. It is useful for maintaining an open airway in an unconscious patient with spontaneous breathing. It should not be inserted in a patient with intact gag reflex. It has the added advantage of assisting with oropharyngeal suctioning and functioning as a bite block. However, incorrect placement can displace the tongue posteriorly, causing inadvertent obstruction of the oropharynx. The correct size is determined by measuring the distance from the centre of the mouth between the first incisors to the angle of the mandible or the distance from the corner of the mouth to the tragus of the ear (same side).

Nasopharyngeal airway (Fig. 6) is an uncuffed soft rubber or plastic tube that can be used in both semiconscious and unconscious patients; it is especially useful in patients with clenched teeth, oral injuries or obstruction. It is contraindicated in mid-face or base-of-skull trauma. The correct length is slightly longer than the distance from the tip of the patient's nose to the earlobe; the diameter of the tube approximates the diameter of the patient's little finger. When inserted correctly, it extends from the external nostrils to the posterior pharynx, just below the base of the tongue.

\section{Endotracheal tube}

Endotracheal tube (ETT) is the definitive airway device that provides a conduit for oxygenation and ventilation, while minimising the risks of aspiration. Suctioning of tracheal secretions can also be performed. The indications for endotracheal intubation include the inability to maintain a patent airway for ventilation despite the use of other airway adjuncts and manoeuvres, protection against aspiration in the unconscious victim and the need for prolonged mechanical ventilation.

The size of the ETT for adults is usually 7.5 (range 7-8.0) and 7.0 (range 6.5-7.5) for men and women, respectively. Preparation of equipment and proper positioning of the patient are vital to

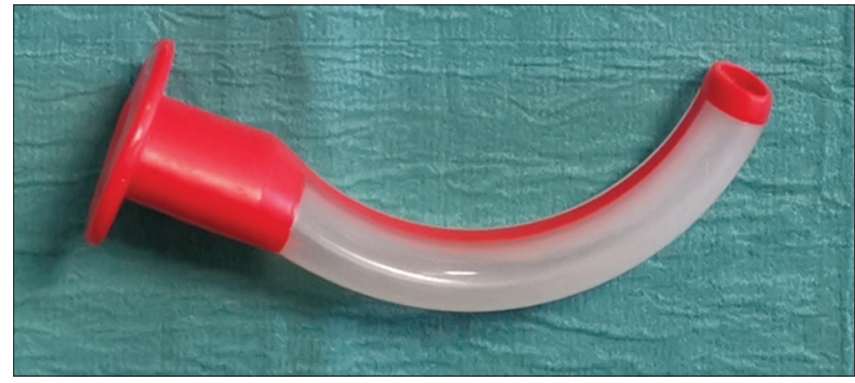

Fig. 5 Photograph shows the oropharyngeal airway, also known as the 'Guedel' airway, in different sizes.

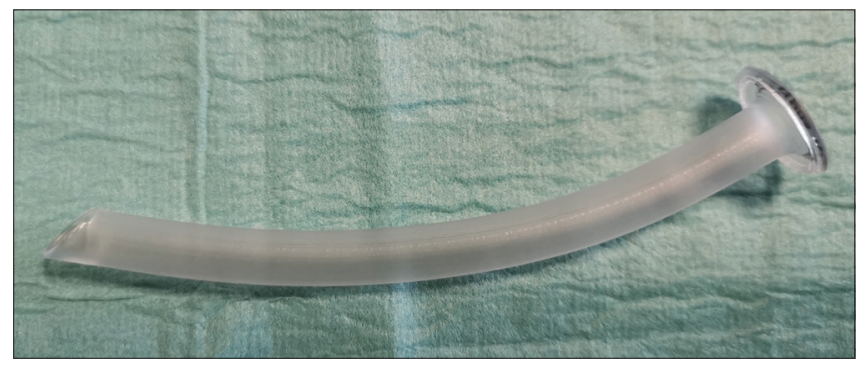

Fig. 6 Photograph shows a nasopharyngeal airway device.

successful intubation. Intubation may be performed using direct laryngoscopy or videolaryngoscopy.

Following intubation, ETT placement may be confirmed by checking for chest rise and fall with assisted ventilations; misting and demisting of the ETT during expiration and inhalation; and by using five-point auscultation, colorimetric capnometry or quantitative waveform capnography using end-tidal carbon dioxide $\left(\mathrm{CO}_{2}\right)$ detectors affixed to the ETT during delivery of BVM ventilations. POCUS may also be used; five-point auscultation is performed, beginning with absent gurgling sounds at the epigastrium followed by equal breath sounds at the upper anterior chest and below the axillae at the midaxillary lines bilaterally. The colorimetric $\mathrm{CO}_{2}$ capnometer has a purple-coloured window when it is freshly removed from the package. This is attached immediately after ETT placement. A change from purple to yellow during exhalation indicates the presence of $\mathrm{CO}_{2}$. Between breaths, the colour may oscillate between purple and yellow. Persistent purple colour or reversion from yellow to purple after six breaths indicates incorrect ETT placement or inadequate perfusion. Quantitative waveform capnography is the most reliable method for confirmation of ETT placement. ${ }^{(28)}$ It has additional advantages of monitoring for ETT dislodgement, as well as reflecting changes in perfusion and response to CPR and resuscitation. Where available, quantitative waveform capnography is recommended for ETT confirmation. Ultrasonography can be used to immediately detect oesophageal intubation ('double tract' sign) during the course of ETT insertion and to confirm proper ETT placement (bilateral lung sliding and curtain sign) after intubation. The use is limited by availability of both equipment and trained operators.

\section{Failure of intubation}

Other than in asphyxiation, the chief priority during cardiac arrest should be restoration of effective circulation through good-quality 
chest compressions. In the event of a failed intubation, the ETT should be removed and BVM ventilation should be recommenced. A laryngeal mask airway (LMA) may be inserted to assist with ventilation prior to re-intubation attempts. Excessive interruptions in chest compressions for repeated intubation attempts should be avoided.

\section{Laryngeal mask airway}

A supraglottic airway such as an LMA (Fig. 7) is an alternative advanced airway device that may be used if direct airway control is desired. Although the size varies according to the type of LMA chosen, in general, sizes 3-5 are used for adult patients. The indications for the use of an LMA include airway protection, ventilation when face-mask ventilation is inadequate and when intubation is difficult or unsuccessful, and facilitation of subsequent insertion of the ETT via an intubating LMA.

The main advantage of the LMA is that it does not require direct visualisation of the glottis, and training and skill maintenance are easier than those required for ETT insertion. If the ETT is already inserted by paramedics for OHCA, the LMA should serve as the primary airway device for resuscitation until equipment and expertise for ETT intubation become available. However, it should not be used in patients with angio-oedema or suspected anaphylaxis.

\section{Supplemental oxygen in resuscitation and oxygen}

\section{delivery devices}

In cardiac arrest, the optimal arterial oxygen saturation $\left(\mathrm{SaO}_{2}\right)$ to be achieved during CPR is not known, although it is generally accepted that supplemental oxygen should be given. Intraarrest hyperoxia has been found to be associated with reduced mortality. ${ }^{(29)}$ When attached to an oxygen source at a flow rate of $10 \mathrm{~L} / \mathrm{min}, \mathrm{BVM}$ ventilation can provide a fraction of inspired oxygen $\left(\mathrm{FiO}_{2}\right.$ ) of up to $85 \%$. It is recommended that the highest deliverable oxygen concentration be used during cardiac arrest.

After ROSC, the $\mathrm{FiO}_{2}$ should be titrated to maintain the patient's $\mathrm{SaO}_{2}$ between $94 \%$ and 98\%. Post-arrest hyperoxaemia should be avoided, as it is associated with poorer survival and neurological outcomes. ${ }^{(30)}$ In a conscious patient with a patent airway, supplemental oxygen can be provided using various devices according to the patient's clinical condition and the desired level of oxygenation.

Nasal cannulae deliver an $\mathrm{FiO}_{2}$ of about $24 \%-44 \%$, through flow rates of $1-6 \mathrm{~L} / \mathrm{min}$. Increase in flow rate by every $1 \mathrm{~L} / \mathrm{min}$ raises $\mathrm{FiO}_{2}$ by about 4\%; however, the increase is highly variable and is affected by proper fit, the patient's respiratory rate, nasal congestion and ambient ventilation. Flow rates above $6 \mathrm{~L} / \mathrm{min}$ cause rapid drying of the nasal mucosa and patient intolerance.

Simple face masks are designed to deliver $\mathrm{FiO}_{2}$ of about $40 \%-60 \%$. This is achieved through a flow of $5-8 \mathrm{~L} / \mathrm{min}$. A minimum flow of $5 \mathrm{~L} / \mathrm{min}$ is required to avoid accumulation of exhaled air in the mask.

Venturi masks have a diluter attached, which entrains air using the Venturi effect to deliver fixed oxygen-air mixtures. The $\mathrm{FiO}_{2}$ is determined by the choice of white or green diluter, the

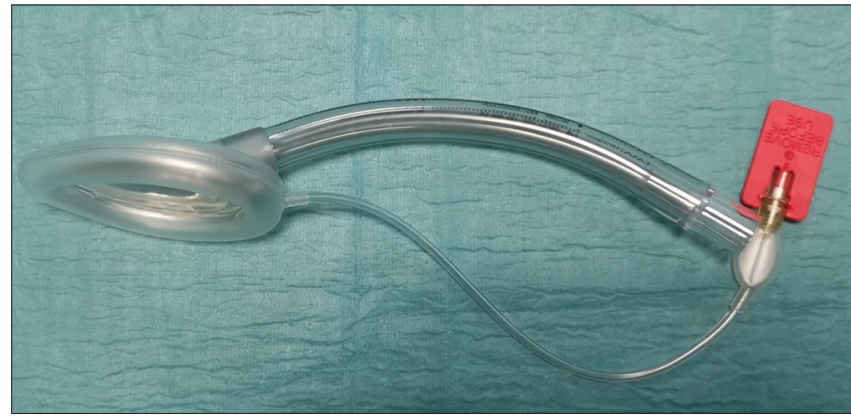

Fig. 7 Photograph shows a laryngeal mask airway device.

size setting of the window, and the corresponding oxygen flow rate from the oxygen source. The low-concentration diluter (green) is used for $\mathrm{FiO}_{2}$ settings of $24 \%-30 \%$ and the high-concentration diluter (white) is used for $\mathrm{FiO}_{2}$ settings of $35 \%-50 \%$. High net flow rates (41-79 L/min) of the oxygen-air mix are achieved. Thus, the set $\mathrm{FiO}_{2}$ is less affected by the seal, patient respiratory effort or environmental ventilation. Venturi masks are, therefore, used in situations where controlled oxygenation is desired, for example, in chronic obstructive pulmonary disease with risk of $\mathrm{CO}_{2}$ retention.

Face masks with reservoir bags deliver high $\mathrm{FiO}_{2}(60 \%-80 \%)$ at a flow rate of $10-15 \mathrm{~L} / \mathrm{min}$. A minimum flow rate of $10 \mathrm{~L} / \mathrm{min}$ is required to inflate the reservoir bag. $\mathrm{High} \mathrm{FiO}_{2}$ of up to $90 \%$ is possible with much higher flow rates, although it never reaches $100 \%$.

\section{Vascular access}

Intravenous access remains the first choice for vascular access. Peripheral large calibre veins, such as the antecubital or external jugular veins, are the most commonly used.

When intravenous access is unsuccessful, difficult or not feasible, intraosseous access is an alternative, but it should not be considered as the first-line access. ${ }^{(31)}$ Insertion sites are at the proximal tibia or the proximal humerus in adults, depending on the user's familiarity with the procedure.

Central venous lines, if already inserted, shorten drug delivery to the central circulation. Central line insertion during resuscitation is likely to interfere with chest compressions owing to the requirement for sterility and access to the neck and upper chest region. Complications include pneumothorax, haemorrhage into the pleural space, inadvertent arterial placement and line sepsis. Central venous lines are, however, ineffective for rapid administration of large fluid volumes.

Implanted vascular access devices such as peripherally inserted central catheters, Port-a-caths or dialysis catheters, may be used with appropriate aseptic technique. Care should also be taken to aspirate solutions, such as alcohol, antibiotics or anticoagulants used to lock these catheters, before drug and fluid administration.

\section{Common drugs in cardiac arrest}

The use of drugs in cardiac arrest remains an adjunct to good-quality chest compressions with minimal interruptions, arrhythmia and ventilation management. Commonly used drugs in cardiac arrest are highlighted here. 
Adrenaline is indicated for VF, pVT, asystole and PEA. Early adrenaline administration is emphasised in this update. ${ }^{(32)}$ Adrenaline should be administered as a 1-mg bolus diluted to $10 \mathrm{~mL}(1: 10,000)$ every $3-5$ minutes. Amiodarone is indicated for refractory or recurrent $\mathrm{VF}$ and $\mathrm{pVT},{ }^{(33)}$ after three shocks or more. The initial bolus dose is $300 \mathrm{mg}$. A repeat bolus of $150 \mathrm{mg}$ can be administered if the rhythm remains refractory to defibrillation. Lignocaine is an alternative for VF and $\mathrm{pVT}$. The initial bolus dose is $1-1.5 \mathrm{mg} / \mathrm{kg}$. A repeat bolus of $0.5-0.75 \mathrm{mg} / \mathrm{kg}$ can be administered if the rhythm remains refractory to defibrillation.

Circulation time during CPR is prolonged. Each drug dose should be flushed with a $20-\mathrm{mL}$ bolus of normal saline while ensuring good-quality CPR to facilitate drug delivery into the central circulation. Owing to the prolonged circulation time, the effects of the drug might not be evident until the next CPR cycle.

\section{Identifying and treating reversible causes of cardiac arrest}

Determining and treating the cause of cardiac arrest are critical to improving patient outcomes. Failure to address the cause will lead to prolonged interval between the time of arrest and ROSC, and increase the risk of subsequent arrest. Reversible causes of cardiac arrest can occur in conditions that are classified under the five $\mathrm{Hs}$ and five Ts (Box 1). Additionally, one must be mindful of other causes of PEA such as non-ischaemic cardiac disorders and intracranial haemorrhage.

POCUS is increasingly used to identify reversible causes of cardiac arrest such as cardiac tamponade or pulmonary embolism. POCUS operators should be skilled to avoid misinterpretation of ultrasonography findings (e.g. right ventricular dilation as a diagnostic indicator of pulmonary embolism, which is of low specificity). In addition, interruption of chest compressions with a transthoracic approach to POCUS should be avoided during cardiac arrest. ${ }^{(34)}$ Breitkrutz et al developed an algorithm of focused echocardiographic evaluation in a time-sensitive manner in coordination with CPR. ${ }^{(35)}$ The use of point-of-care echocardiography for prognostication is not recommended, as most studies that used this method reported low sensitivity and low specificity for outcomes. ${ }^{(36)}$

\section{Extracorporeal CPR}

Extracorporeal CPR (eCPR) is the initiation of venoarterial extracorporeal membrane oxygenation (VA-ECMO) to provide circulatory support in patients in whom conventional CPR is unsuccessful in achieving sustained ROSC. The goal of eCPR is to support end organ perfusion while potentially reversible causes are treated. eCPR is a highly complex intervention requiring considerable resources and experienced teams for effective implementation. Currently, no published randomised controlled trials of eCPR for OHCA or IHCA exist. Observational studies have been assessed to have serious risk of bias and low overall certainty of evidence for all important patient outcomes. ${ }^{(37)}$ Hence, routine use of eCPR for patients with cardiac arrest is currently not recommended. eCPR may be considered for carefully selected patients with cardiac arrest for whom the suspected cause is

\begin{tabular}{|l|}
\hline Box 1. Reversible causes of cardiac arrest: \\
Five Hs: \\
• Hypoxia \\
• Hypovolaemia \\
- Hydrogen ion acidosis \\
- Hyper- or hypokalaemia \\
- Hypothermia \\
Five Ts: \\
- Toxic ingestions \\
- Tamponade (cardiac) \\
- Tension pneumothorax \\
- Thrombosis - coronary or pulmonary \\
- Trauma
\end{tabular}

potentially reversible during a limited period of mechanical cardiorespiratory support. The common circumstances where eCPR would be offered require the presence of the following:

- Witnessed cardiac arrest with immediate high-quality CPR

- A reversible cause for cardiac arrest in a young patient

- $\quad$ eCPR can be implemented rapidly from the time of cardiac arrest

- No contraindications to ECMO (such as the presence of multiple organ failure, advanced malignancy, severe chronic organ failure, severe brain injury, uncontrolled bleeding, and pre-existing 'Do Not Resuscitate' order)

\section{Post-resuscitation care}

ROSC is when a pulse is present during the two-minute rhythm check. A systematic approach to post-cardiac arrest care is critical to increase the patient's chance of survival with good functional recovery. These measures include: (a) targeted temperature management with a selected constant temperature between $32^{\circ} \mathrm{C}$ and $36^{\circ} \mathrm{C}$ for at least 24 hours and subsequent gradual rewarming; (b) emergent coronary angiography for patients with suspected cardiac cause of arrest and ST segment elevation on ECG; (c) avoidance of hypotension by maintaining a mean arterial pressure of at least $65 \mathrm{mmHg}$; (d) avoidance of hypoxaemia/ hyperoxia and maintenance of normocarbia; (e) detection and treatment of active seizures, if present; and ( $f$ ) performance of multimodal neuroprognostication at a minimum of 72 hours after normothermia. These measures are described further in a separate section on post-resuscitation management. ${ }^{(38)}$

\section{Organ donation}

On comparing organs from donors who experienced brain death after cardiac arrest with those from donors with other causes of brain death, we observed that the short-term and long-term functional outcomes of these organs were similar in various transplant registries. Donation after circulatory death (controlled or uncontrolled) is increasingly being performed worldwide with similar success outcomes, especially for kidneys and lung transplantation. ${ }^{(39,40)}$ This will require donation in settings where there is an established programme and would be subjected to existing law and regulations in Singapore. 


\section{PERI-ARREST ALGORITHMS}

A haemodynamically unstable patient may have symptoms of syncope, chest pain, altered mental state, diaphoresis or dyspnoea and may present with hypotension or heart failure. Such life-threatening states may arise from cardiac aetiologies such as tachy- or bradydysrhythmias, although other forms of shock including hypovolaemic, haemorrhagic, distributive or obstructive shock must be considered and managed when present.

The initial approach of ACLS to dysrhythmia management has been standardised across the various algorithms. It starts with an assessment of the patient's clinical stability, measurement of vital signs, establishment of adequate airway and vascular access, and analysis of the rhythm with a 12-lead ECG or defibrillator monitor. These patients should ideally be nursed in a clinical area that is equipped for resuscitation. The specific algorithms to undertake depend on the nature of the dysrhythmia and the haemodynamic stability of the patient.

\section{Narrow complex tachycardia}

Tachycardia occurs when the heart rate is $\geq 100$ beats per minute (bpm). The diagnosis and management depend on the width of the QRS complex. Narrow complex tachycardia (NCT) represents a range of tachyarrhythmias originating from a circuit or focus involving the atria or atrioventricular (AV) node.

The management of patients with NCT is based on the diagnosis of the tachyarrhythmia and on whether the patients are haemodynamically compromised i.e. having ischaemic change pain, altered mental status, hypotension, shock, acute heart failure, etc.

\section{Sinus tachycardia}

In sinus tachycardia, patients may not complain of palpitations and clinical features, and treatment is targeted at the underlying causes. The causes of sinus tachycardia include:

- Shock (hypovolaemic, septic, obstructive, distributive and cardiogenic)

- Hyperdynamic state (thyrotoxicosis, fever, drug, anaemia, hypoxia)

- $\quad$ Anxiety, pain

\section{Supraventricular tachycardia}

Supraventricular tachycardia (SVT) may be due to AV nodal reentry or AV re-entry tachycardia. Patients usually have a sudden onset of symptoms (palpitations). Diagnosis is usually made after a 12-lead ECG is performed.

\section{Unstable patients}

Patients with SVT who have serious signs and symptoms of instability should be treated with a rapid intravenous bolus of adenosine $6 \mathrm{mg}$ via a proximal large calibre vein, followed immediately by a $20-\mathrm{mL}$ saline flush using a three-way connector. ${ }^{(41)}$ This may be repeated with $12 \mathrm{mg}$, followed by $18 \mathrm{mg}$ if the initial bolus is unsuccessful. ${ }^{(42)}$ The patient must be warned of side effects of transient chest tightness, bronchospasm and hot facial flushes soon after drug administration. An alternative method of administration has been described, ${ }^{(43)}$ where the dose of adenosine is first mixed into the saline flush and the mixture is administered as a single bolus. There is no difference in the success rates between the two methods.

If intravenous adenosine is unsuccessful, urgent synchronised cardioversion should be performed. The procedure for synchronised cardioversion involves the following steps: (1) explain the procedure to the patient; (2) provide analgesia and sedation carefully in titrated doses; (3) apply the defibrillation pads to the patient; (4) ensure that the 'Sync' function is activated on the defibrillator; (5) select the energy starting at $50 \mathrm{~J}$ and escalate if unsuccessful; (6) ensure safety, stand clear and deliver the cardioversion shock; and (7) reassess the patient's rhythm and vital signs. This should be performed under full rhythm and haemodynamic monitoring.

\section{$\underline{\text { Stable patients }}$}

If vital signs are normal, without any serious signs and symptoms, nonpharmacological cardioversion using vagal manoeuvres such as carotid sinus massage or the modified Valsalva manoeuvre may initially be attempted before using pharmacological agents.

The classical Valsalva manoeuvre is now replaced by the modified Valsalva technique. ${ }^{(44)}$ When performing the procedure: (a) explain the procedure to the patient; (b) position the patient in the trolley with the head of the trolley raised to a $45^{\circ}$ angle; and (c) have the patient perform a forced expiration against resistance by blowing into the nozzle of a $10-\mathrm{mL}$ syringe or using a hand-held manometer to reach an airway pressure of $40 \mathrm{mmHg}$ and sustain it for at least 15 seconds. (d) Once the patient releases the strain, lower the head of the trolley to lay the patient flat and have an assistant raise the patient's legs to about $45^{\circ}$; and (e) monitor the rhythm for conversion. The conversion takes place after the increased venous return from the raised legs returns to the heart.

The carotid sinus massage should be avoided in older patients; patients with known cardiovascular diseases; and patients with a history of transient ischaemic attack, stroke and the presence of carotid bruit, so as to avoid the risk of causing a stroke. When performing the procedure: (a) explain the procedure to the patient; (b) lay the patient flat to distend the carotid sinus; (c) localise the carotid sinus by feeling for the pulsation between the upper border of the thyroid cartilage and the anterior border of the sternocleidomastoid muscle; (d) apply firm pressure on this site by pressing the carotid sinus against the transverse processes of the cervical vertebrae using the thumb or fingers in a circular or linear motion for 10-15 seconds; (e) monitor the cardiac rhythm; and ( $f$ ) if unsuccessful, attempt massage of the opposite carotid sinus. Do not massage both sides at the same time.

In case of unsuccessful attempts with vagal manoeuvres, pharmacological agents may be employed to achieve rhythm control (i.e pharmacological cardioversion). Intravenous adenosine and intravenous calcium channel blockers verapamil and diltiazem ${ }^{(45)}$ are all acceptable drugs of first choice for the conversion of stable patients with SVT. Intravenous verapamil can be administered as an infusion at a rate of $1 \mathrm{mg} / \mathrm{min}$, up to a 
maximum of $20 \mathrm{mg}$, with haemodynamic monitoring at two-minute intervals. The infusion is stopped once sinus rhythm is achieved.

Intravenous diltiazem is infused at a rate of $2.5 \mathrm{mg} / \mathrm{min}$ up to a maximum of $50 \mathrm{mg}$, with haemodynamic monitoring at two-minute intervals. The infusion is stopped once conversion to sinus rhythm is achieved.

\section{Atrial fibrillation}

Atrial fibrillation (AF) occurs when structural and/or electrophysiological abnormalities alter the atrial tissue to promote abnormal impulse formation and/or propagation. These abnormalities are caused by diverse pathophysiological mechanisms. Multiple clinical risk factors are associated with an increased risk of $\mathrm{AF}$, such as valvular heart disease, increasing age, hypertension, diabetes mellitus, myocardial infarction, heart failure, obesity, obstructive sleep apnoea, cardiothoracic surgery, alcohol use and hyperthyroidism.

\section{$\underline{\text { Unstable patients }}$}

Patients presenting with $\mathrm{AF}$ with rapid ventricular response may develop haemodynamic or clinical instability. Patients with fast ventricular rates in AF may also have another pathology that causes the instability, such as sepsis or dehydration (similar to the causes of sinus tachycardia), which must be treated first. If the rhythm itself is assessed to be the primary cause of instability, synchronised cardioversion with procedural sedation (described above) would be required for urgent rhythm control. ${ }^{(46)}$ The shock energy should begin at $100 \mathrm{~J}$ and be escalated if necessary. The coagulation status of the patient should be checked and IV heparin should be administered before cardioversion.

\section{Stable patients}

For rate control of $\mathrm{AF}$ in the absence of heart failure, slow infusion of diltiazem may be administered at a rate of $2.5 \mathrm{mg}$ over three minutes, up to a maximum dose of $50 \mathrm{mg}$, with haemodynamic monitoring, to achieve controlled ventricular response. Shortacting beta-blockers are suitable alternatives, particularly for AF associated with thyrotoxicosis. They should be avoided in the presence of heart failure owing to a possible negative inotropic effect. The currently recommended treatment for patients with heart failure is infusion of amiodarone $300 \mathrm{mg}$ over a 60-minute period, with frequent monitoring of blood pressure owing to the blood-pressure-lowering effects of amiodarone. ${ }^{(47)}$ Care should be taken in patients with thyroid disease. IV digoxin $0.5 \mathrm{mg}$ infused over 30 minutes is an alternative, but it will take effect only several hours later. ${ }^{(48)}$ Other aspects regarding the management of $\mathrm{AF}$, such as details about anticoagulation, are beyond the scope of these guidelines.

\section{Wide complex tachycardia}

The majority of regular wide complex tachycardias (WCTs) are due to VT; a small subset is due to SVT with aberrancy. Even less common causes would include Wolff-Parkinson-White (WPW) ECG, drugs (e.g. flecainide), electrolyte abnormalities or cardiac pacing (e.g. pacemakers). ${ }^{(49)}$
The presence of a pre-existing structural cardiac disease (such as ischaemic heart disease or cardiac failure) increases the already high likelihood of the WCT being due to VT. Specific ECG features such as AV dissociation would also confirm a diagnosis of VT. (50) However, if the patient's baseline ECG already demonstrates a wide QRS morphology that is similar to the patient's current WCT, SVT with aberrancy or WPW should be considered. ${ }^{(51)}$ In case of clinical uncertainty, the patient should be managed in the same way as a patient with VT would be (Fig. 10 shows the algorithm for WCT).

\section{Unstable patients}

Patients with WCT and symptoms/signs of haemodynamic instability (e.g. syncope, diaphoresis or hypotension) should be treated rapidly with urgent synchronised cardioversion with starting shock energy of $100 \mathrm{~J}$, as described above. If the initial shock is unsuccessful, escalate the energy level to the maximum level permitted by the defibrillator; if WCT becomes irregular (polymorphic VT or VF), turn off the 'Sync' and defibrillate without synchronisation. ${ }^{(52,53)}$ Once converted, start amiodarone infusion $1 \mathrm{mg} / \mathrm{min}$ for the first six hours, followed by $0.5 \mathrm{mg} / \mathrm{min}$ for the next 18 hours. Amiodarone is preferred over lignocaine. If long QTc is suspected, lignocaine should be used instead at $1-2 \mathrm{mg} / \mathrm{min}$ for 24 hours.

\section{$\underline{\text { Stable patients }}$}

Patients with haemodynamically stable (blood pressure $>90 / 45 \mathrm{mmHg}$ ) regular WCT and no serious signs/symptoms should first undergo a 12-lead ECG. These patients should be closely monitored, as they may deteriorate and become unstable. The cardiology service should be consulted, if available. Under certain circumstances, a rapid push of intravenous adenosine $6 \mathrm{mg}$ or $12 \mathrm{mg}$ may be helpful to differentiate the different causes of a stable regular WCT (a defibrillator should be present), such as in a patient with a known history of SVT with aberrancy. Pharmacological cardioversion of VT involves the following steps: (a) explain the procedure to the patient; (b) administer IV amiodarone $150 \mathrm{mg}$ diluted in $100 \mathrm{~mL}$ of D5\% infused over 15 minutes. Do not dilute amiodarone in normal saline, as it will precipitate; (c) repeat once if the first dose was unsuccessful. Watch for hypotension; (d) a second-line alternative to amiodarone is lignocaine infusion at $10 \mathrm{mg} / \mathrm{min}$ (at a dose of $1.5 \mathrm{mg} / \mathrm{kg}$ ), which is repeated once if the first dose was unsuccessful; (e) if drug therapy fails or patient becomes unstable, perform electrical cardioversion as per unstable patients (see above); and (f) upon successful conversion to sinus rhythm, provide a maintenance infusion (amiodarone $0.5 \mathrm{mg} / \mathrm{min}$ or lignocaine $1 \mathrm{mg} / \mathrm{min}$ ).

\section{Polymorphic VT}

Polymorphic VT or torsades de pointes (in prolonged QTC) frequently results in haemodynamic instability requiring urgent cardioversion. Do not turn on 'Sync' as the defibrillator may be unable to detect and synchronise to any R wave, delaying the shock.

If a patient has long QTc, intravenous magnesium sulphate 1-2 g over 15 minutes should be administered. In polymorphic 


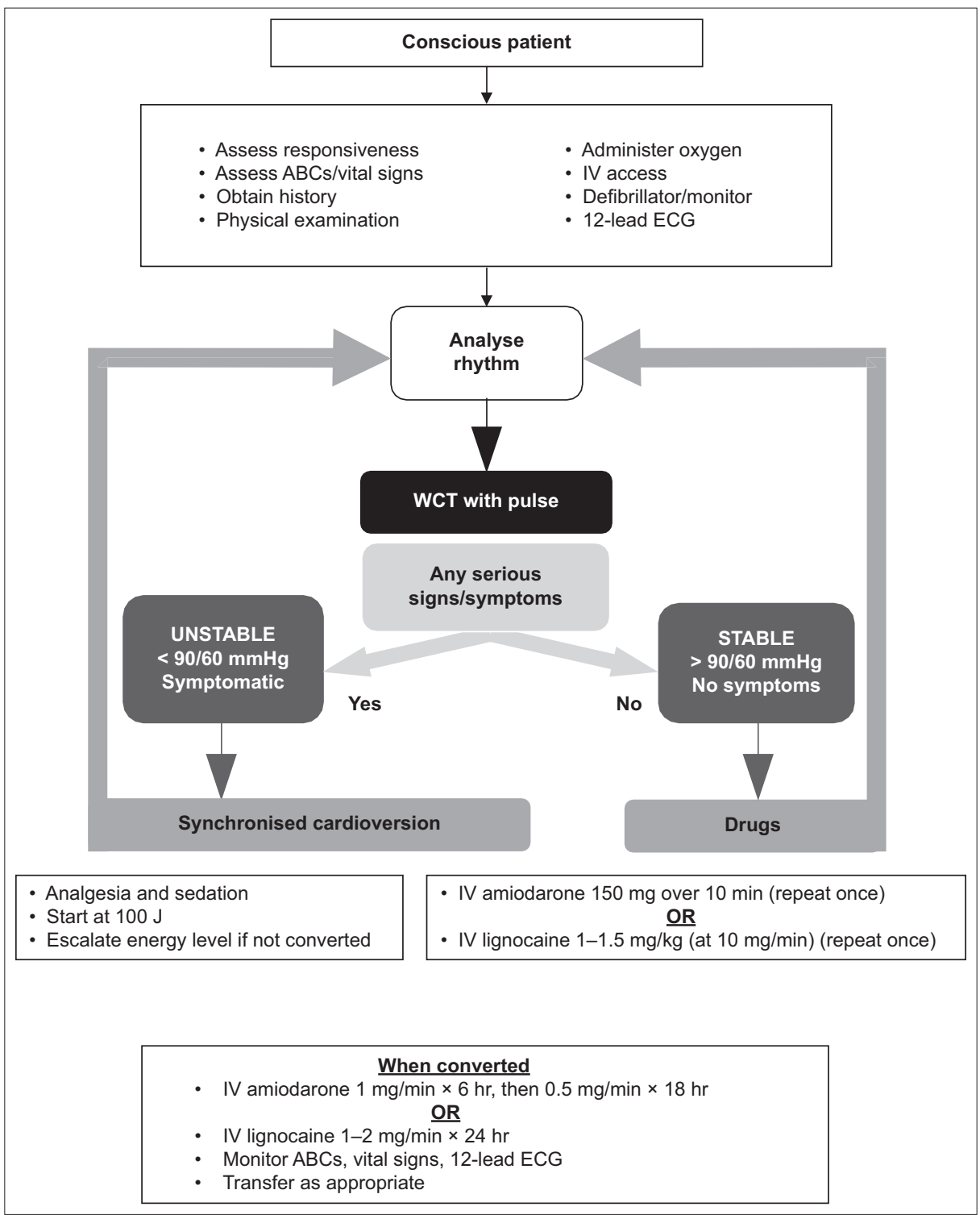

Fig. 8 Flowchart shows the algorithm for wide complex tachycardia. ECG: electrocardiography; IV: intravenous; WCT: wide complex tachycardia

VT with normal QTC, intravenous amiodarone infusion of $150 \mathrm{mg}$ diluted in $100 \mathrm{~mL}$ of D5\% over 15 minutes may be administered. Amiodarone should be avoided in long QTC.

\section{Bradycardia}

Haemodynamically significant bradyarrhythmias usually present with a heart rate below $60 \mathrm{bpm}$ and a blood pressure below $90 / 60 \mathrm{mmHg}$. Most symptomatic patients tend to have heart rates even lower than $50 \mathrm{bpm}$. Asymptomatic and haemodynamically stable patients generally do not require further treatment for the bradycardia. However, patients with Mobitz Type II second-degree or complete heart blocks should be monitored closely even if they are stable, as they are at risk of sudden deterioration. Unstable patients should be managed in a monitored area and provided supplemental oxygen or ventilatory assistance, as appropriate. A 12-lead ECG or rhythm strip should be obtained to analyse the rhythm. The algorithm for bradyarrhythmias is shown in Fig. 9.

The common drugs that may be used for bradyarrhythmias are atropine, dopamine infusion and adrenaline infusion. Atropine for bradycardia is given in repeated boluses of $0.6 \mathrm{mg}$, up to a maximum vagolytic dose of $2.4 \mathrm{mg}$. Dopamine infusion is started at a rate of $5-20 \mathrm{mcg} / \mathrm{kg} / \mathrm{min}$ and increased to a maximum of $20 \mathrm{mcg} / \mathrm{kg} / \mathrm{min}$, above which the likelihood of peripheral and splanchnic vasoconstriction may be significant and undesirable. Adrenaline infusion for bradycardia is initiated at a rate of $2-10 \mathrm{mcg} / \mathrm{min}$ and increased gradually till the target heart rate and/or blood pressure is achieved.

Cardiac pacing would have to be considered for all patients with haemodynamically significant bradycardia. In an emergency situation, transcutaneous pacing is the preferred method until transvenous pacing can be organised. Transcutaneous pacing is painful in conscious patients, and requires analgesia and sedation.

\section{ACLS IN SPECIAL CIRCUMSTANCES Drowning}

The survival rate of cardiac arrest associated with drowning is $13 \%{ }^{(54)}$ Drowning victims die from hypoxaemia, and the duration and severity of hypoxia are the most important determinants of 


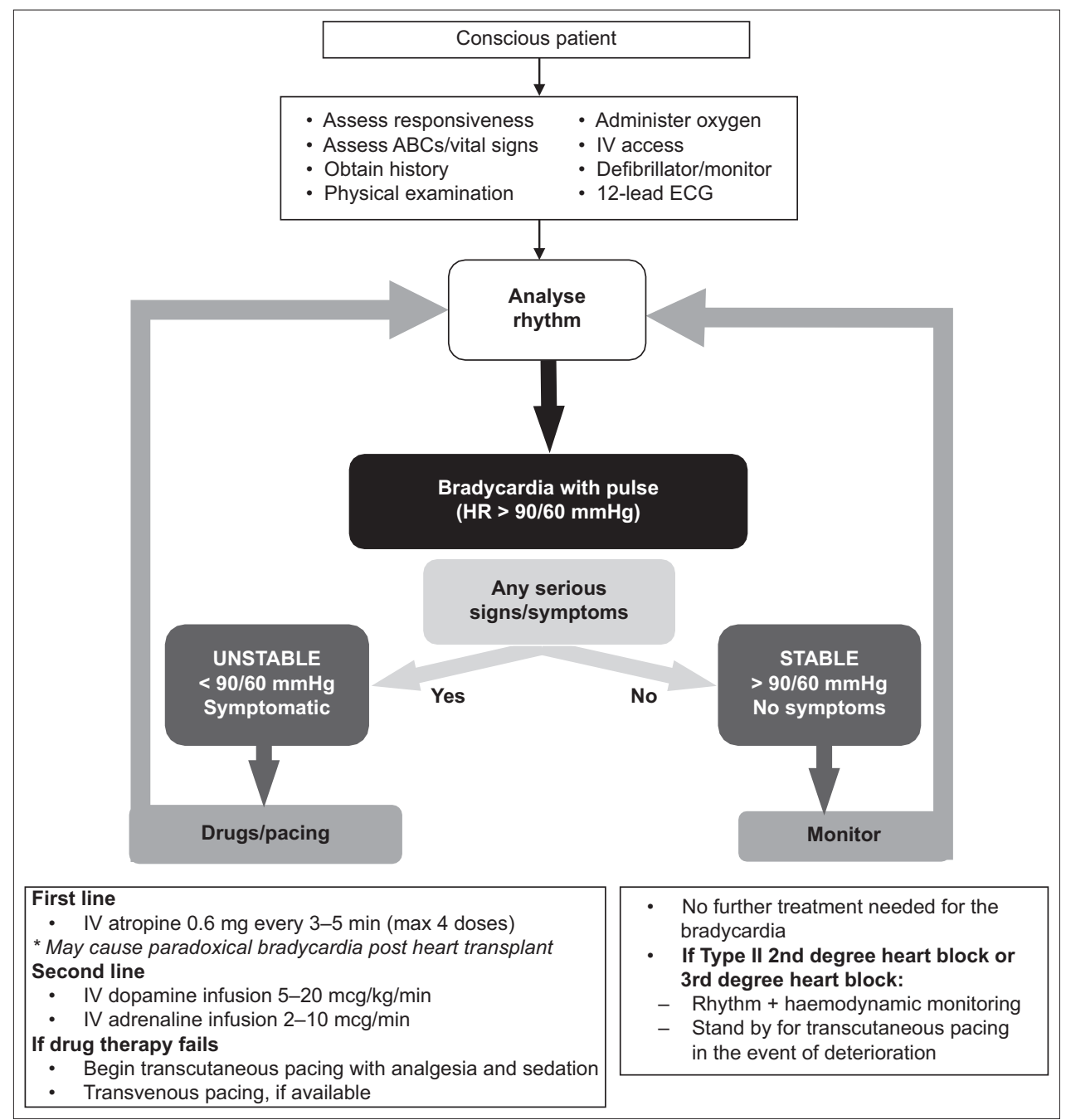

Fig. 9 Flowchart shows the algorithm for bradycardia. ECG: electrocardiography; IV: intravenous

mortality. ${ }^{(55,56)}$ Therefore, rescue breathing should be prioritised once the victim is brought ashore (or initiated while in-water by trained rescuers). ${ }^{(57)}$ If the victim is pulseless, chest compressions and BCLS should be administered, and in the absence of obvious signs of death, all drowning victims in cardiac arrest should be evacuated to a hospital, as survival after prolonged submersion, although rare, has been reported. ${ }^{(58)}$ Unless there is suspicion of spinal injury, routine cervical spine stabilisation of drowning victims delays resuscitation and is not required. ${ }^{(59)}$ Near-drowning victims who are revived at the scene but had required any form of resuscitation after fresh- or salt-water submersion should be transported to a hospital and monitored for 4-6 hours for delayed decompensation. ${ }^{(60,61)}$

\section{Pulmonary embolism}

Fulminant pulmonary embolism (PE) (massive PE that results in haemodynamic instability or arrest) is a reversible cause of cardiac arrest, with PEA being the predominant presenting rhythm. ${ }^{(62)}$ Anticoagulation alone is inadequate for patients with cardiac arrest with confirmed fulminant PE, and systemic thrombolysis or surgical/percutaneous mechanical embolectomy is required to rapidly reverse pulmonary artery occlusion. ${ }^{(63,64)}$ The choice of intervention depends on the timing and available expertise.
For patients with cardiac arrest where PE is suspected but not confirmed, evidence suggests that major bleeding risk is not significantly higher in patients undergoing thrombolysis ${ }^{(65)}$ and the risk of death is greater from doing nothing; hence, empirical thrombolysis should be considered. ${ }^{(54)}$ eCPR may potentially facilitate the use of fibrinolysis or mechanical or surgical embolectomy $^{(66)}$ and may be considered if expertise is available.

\section{Cardiac arrest in pregnancy}

The best outcomes for both mother and fetus are achieved through successful maternal resuscitation. Common causes of cardiac arrest in pregnancy include haemorrhage, eclampsia, amniotic fluid embolism, heart failure, sepsis, aspiration pneumonia and pulmonary embolism. ${ }^{(67,68)}$ Standard BCLS and ACLS should be performed with the following special considerations.

- $\quad$ Owing to reduced maternal functional respiratory reserves and fetal susceptibility to hypoxia, an advanced airway is required to optimise ventilation and oxygenation. Anticipate a difficult airway owing to anatomical changes in pregnancy.

- $\quad$ From 20 weeks' gestation onwards (fundal height at the level of the umbilicus), mothers are prone to hypotension from aortocaval compression, reducing venous return to the 
heart. This should be countered by continuous left lateral uterine displacement during resuscitation.

- During maternal resuscitation, fetal monitoring is not indicated as it distracts from, and interferes with, resuscitative efforts.

- $\quad$ Perimortem Caesarean delivery (PMCD) during cardiac arrest for women in the second half of pregnancy is associated with ROSC and improved neonatal survival. For best outcomes, PMCD should be performed within five minutes of cardiac arrest. ${ }^{(69)}$ Therefore, summoning resources and preparing for PMCD early in the course of resuscitation will allow it to be initiated expeditiously if there is no ROSC within the above time frame. ${ }^{(70)}$ For nonsurvivable maternal situations, prompt PMCD is associated with improved neonatal survival. ${ }^{(71)}$

- $\quad$ Post-resuscitation care:

a. Previous case series report good maternal survival when ECMO is initiated in maternal cardiac arrest. ${ }^{(72)}$

b. Targeted temperature management (TTM) is indicated for pregnant patients who remain comatose after ROSC. ${ }^{\text {(73) }}$ A potential complication of TTM is fetal bradycardia, which requires continuous fetal monitoring and co-management with obstetrics and neonatology.

\section{REFERENCES}

1. Ching CK, Leong SH, Chua SJ, et al; National Resuscitation Council Singapore. Advanced Cardiac Life Support: 2016 Singapore Guidelines. Singapore Med J 2017; 58:360-72.

2. White AE, Ho AFW, Shahidah N, et al. An essential review of Singapore's response to out-of-hospital cardiac arrests: improvements over a ten-year period. Singapore Med J 2021; 62:438-43.

3. Ng YY, Leong SH, Ong ME. The role of dispatch in resuscitation. Singapore Med J 2017; 58:449-52.

4. Ng QX, Han MX, Lim YL, Arulanandam S. A systematic review and meta-analysis of the implementation of high-performance cardiopulmonary resuscitation on out-of-hospital cardiac arrest outcomes. J Clin Med 2021; 10:2098.

5. Ong ME, Yan X, Lau G, et al. Out-of-hospital cardiac arrests occurring in primary health care facilities in Singapore. Resuscitation 2007; 74:38-43.

6. Yeung J, Matsuyama T, Bray J, Reynolds J, Skrifvars MB. Does care at a cardiac arrest centre improve outcome after out-of-hospital cardiac arrest? - A systematic review. Resuscitation 2019; 137:102-15.

7. Findlay GP, Shotton H, Kelly K, Mason M. Time to intervene? A review of patients who underwent cardiopulmonary resuscitation as a result of an in-hospital cardiorespiratory arrest. In: the National Confidential Enquiry into Patient Outcome and Death. Available at: https://www.ncepod.org.uk/2012report1/ downloads/CAP_fullreport.pdf. Accessed June 1, 2021.

8. Baxter AD, Cardinal P, Hooper J, Patel R. Medical emergency teams at The Ottawa Hospital: the first two years. Can J Anaesth 2008; 55:223-31.

9. Benson L, Mitchell C, Link M, Carlson G, Fisher J. Using an advanced practice nursing model for a rapid response team. Jt Comm J Qual Patient Saf 2008; 34:743-7.

10. Buist MD, Moore GE, Bernard SA, et al. Effects of a medical emergency team on reduction of incidence of and mortality from unexpected cardiac arrests in hospital: preliminary study. BMJ 2002; 324:387-90.

11. Buist M, Harrison J, Abaloz E, Van Dyke S. Six year audit of cardiac arrests and medical emergency team calls in an Australian outer metropolitan teaching hospital. BMJ 2007; 335:1210-2.

12. Institute for Healthcare Improvement. Rapid response teams. Available at: www.ihi.org/Topics/RapidResponseTeams/Pages/default.aspx. Accessed March 3, 2021.

13. Jones D, Moran J, Winters B, Welch J. The rapid response system and end-of-life care. Curr Opin Crit Care 2013; 19:616-23.

14. Lim SH, Chee TS, Wee FC, et al. Singapore Basic Cardiac Life Support and Automated External Defibrillation Guidelines 2021. Singapore Med J 2021; 62:415-23.

15. Gugelmin-Almeida D, Tobase L, Facholi Polastri T, Ciqueto Peres HH, Timerman S. Do automated real-time feedback devices improve CPR quality? A systematic review of literature. Resusc Plus 2021; 6:100108.

16. Zhu N, Chen Q, Jiang Z, et al. A meta-analysis of the resuscitative effects of mechanical and manual chest compression in out-of-hospital cardiac arrest patients. Crit Care 2019; 23:100.

17. Anantharaman V, Ng BL, Ang SH, et al. Prompt use of mechanical cardiopulmonary resuscitation in out-of-hospital cardiac arrest: the MECCA study report. Singapore Med J 2017; 58:424-31.

18. Couper K, Velho RM, Quinn T, et al. Training approaches for the deployment of a mechanical chest compression device: a randomised controlled manikin study. BMJ Open 2018; 8:e019009.

19. Walsh SJ, McCarty D, McClelland AJ, et al. Impedance compensated biphasic waveforms for transthoracic cardioversion of atrial fibrillation: a multi-centre comparison of antero-apical and antero-posterior pad positions. Eur Heart J 2005; 26:1298-302.

20. Kramer-Johansen J, Edelson DP, Abella BS, et al. Pauses in chest compression and inappropriate shocks: a comparison of manual and semi-automatic defibrillation attempts. Resuscitation 2007; 73:212-20.

21. Kudenchuk PJ, Cobb LA, Copass MK, et al. Transthoracic incremental monophasic versus biphasic defibrillation by emergency responders (TIMBER): a randomized comparison of monophasic with biphasic waveform ascending energy defibrillation for the resuscitation of out-of-hospital cardiac arrest due to ventricular fibrillation. Circulation 2006; 114:2010-8.

22. Rea TD, Helbock M, Perry S, et al. Increasing use of cardiopulmonary resuscitation during out-of-hospital ventricular fibrillation arrest: survival implications of guideline changes. Circulation 2006; 114:2760-5.

23. Anantharaman V, Tay SY, Manning PG, et al. A multicenter prospective randomized study comparing the efficacy of escalating higher biphasic versus low biphasic energy defibrillations in patients presenting with cardiac arrest in the in-hospital environment. Open Access Emerg Med 2017; 9:9-17.

24. Deakin CD, Morley P, Soar J, Drennan IR. Double (dual) sequential defibrillation for refractory ventricular fibrillation cardiac arrest: a systematic review. Resuscitation 2020; 155:24-31.

25. Stiell IG, Nichol G, Leroux BG, et al; ROC Investigators. Early versus later rhythm analysis in patients with out-of-hospital cardiac arrest. N Engl J Med 2011; 365:787-97.

26. Bircher NG, Chan PS, Xu Y; American Heart Association's Get With The Guidelines-Resuscitation Investigators. Delays in cardiopulmonary resuscitation, defibrillation, and epinephrine administration all decrease survival in in-hospital cardiac arrest. Anesthesiology 2019; 130:414-22.

27. Cheskes S, Schmicker RH, Verbeek PR, et al. The impact of peri-shock pause on survival from out-of-hospital shockable cardiac arrest during the Resuscitation Outcomes Consortium PRIMED trial. Resuscitation 2014; 85:336-42.

28. Grmec S. Comparison of three different methods to confirm tracheal tube placement in emergency intubation. Intensive Care Med 2002; 28:701-4.

29. Patel JK, Kataya A, Parikh PB. Association between intra- and post-arrest hyperoxia on mortality in adults with cardiac arrest: a systematic review and meta-analysis. Resuscitation 2018; 127:83-8.

30. Roberts BW, Kilgannon JH, Hunter BR, et al. Association between early hyperoxia exposure after resuscitation from cardiac arrest and neurological disability: prospective multicenter protocol-directed cohort study. Circulation 2018; 137:2114-24.

31. Granfeldt A, Avis SR, Lind PC, et al. Intravenous vs. intraosseous administration of drugs during cardiac arrest: a systematic review. Resuscitation 2020; 149:150-7.

32. Perkins GD, Kenna C, Ji C, et al. The influence of time to adrenaline administration in the Paramedic 2 randomised controlled trial. Intensive Care Med 2020; 46:426-36.

33. Kudenchuk PJ, Brown SP, Daya M, et al. Amiodarone, lidocaine, or placebo in out-of-hospital cardiac arrest. N Engl J Med 2016; 374:1711-22.

34. Huis in 't Veld MA, Allison MG, Bostick DS, et al. Ultrasound use during cardiopulmonary resuscitation is associated with delays in chest compressions. Resuscitation 2017; 119:95-8.

35. Breitkreutz R, Walcher F, Seeger FH. Focused echocardiographic evaluation in resuscitation management: concept of an advanced life support-conformed algorithm. Crit Care Med 2007; 35(5 Suppl):S150-61.

36. Reynolds JC, Issa MS, Nicholson TC, et al; Advanced Life Support Task Force of the International Liaison Committee on Resuscitation. Prognostication with point-of-care echocardiography during cardiac arrest: a systematic review. Resuscitation 2020; 152:56-68.

37. Holmberg MJ, Geri G, Wiberg S, et al; International Liaison Committee on Resuscitation's (ILCOR) Advanced Life Support and Pediatric Task Forces. Extracorporeal cardiopulmonary resuscitation for cardiac arrest: a systematic review. Resuscitation 2018; 131:91-100.

38. Chia YW, Lim SL, Loh JK, Leong BSH, Ong MEH; Singapore National Targeted Temperature Management Workgroup. Beyond return of spontaneous circulation: update on post-cardiac arrest management in the intensive care unit. Singapore Med J 2021; 62:444-51.

39. Van Raemdonck D, Keshavjee S, Levvey B, et al; International Society for Heart and Lung Transplantation. Donation after circulatory death in lung transplantation-five-year follow-up from ISHLT Registry. J Heart Lung Transplant 
$2019 ; 38: 1235-45$

40. Bell R, Farid S, Pandanaboyana S, et al. The evolution of donation after circulatory death renal transplantation: a decade of experience. Nephrol Dia Transplant 2019; 34:1788-98.

41. Lim SH, Anantharaman V, Teo WS, Chan YH. Slow infusion of calcium channel blockers compared with intravenous adenosine in the emergency treatment of supraventricular tachycardia. Resuscitation 2009; 80:523-8.

42. Delaney B, Loy J, Kelly AM. The relative efficacy of adenosine versus verapami for the treatment of stable paroxysmal supraventricular tachycardia in adults: a meta-analysis. Eur J Emerg Med 2011; 18:148-52.

43. Choi SC, Yoon SK, Kim GW, et al. A convenient method of adenosine administration for paroxysmal supraventricular tachycardia. J Korean Soc Emerg Med 2003; 14:224-7.

44. Appelboam A, Reuben A, Mann C, et al; REVERT trial collaborators. Postura modification to the standard Valsalva manoeuvre for emergency treatment of supraventricular tachycardias (REVERT): a randomised controlled trial. Lance 2015; 386:1747-53.

45. Lim SH, Anantharaman V, Teo WS. Slow-infusion of calcium channel blocker in the emergency management of supraventricular tachycardia. Resuscitation $2002 ; 52: 167-74$

46. Raymond RJ, Lee AJ, Messineo FC, Manning WJ, Silverman DI. Cardiac performance early after cardioversion from atrial fibrillation. Am Heart J 1998 136:435-42.

47. Delle Karth G, Geppert A, Neunteufl T, et al. Amiodarone versus diltiazem for rare control in critically ill patients with atrial tachyarrhythmias. Crit Care Med 2001; 29:1149-53.

48. January CT, Wann LS, Calkins H, et al. 2019 AHA/ACC/HRS focused update of the $2014 \mathrm{AHA} / \mathrm{AA} / \mathrm{HRS}$ guideline for the management of patients with atria fibrillation: a report of the American College of Cardiology/American Heart Association Task Force on Clinical Practice Guidelines and the Heart Rhythm Society in collaboration with the Society of Thoracic Surgeons. Circulation 2019; 140:e125-51.

49. Vereckei A. Current algorithms for the diagnosis of wide QRS complex tachycardias. Curr Cardiol Rev 2014; 10:262-76.

50. Kashou AH, Noseworthy PA, DeSimone CV, et al. Wide complex tachycardi differentiation: a reappraisal of the state-of-the-art. J Am Heart Assoc 2020; 9:e016598.

51. Evenson CM, Kashou AH, LoCoco S, et al. Conceptual and literature basis for wide complex tachycardia and baseline ECG comparison. J Electrocardiol 2021; 65:50-4

52. Panchal AR, Bartos JA, Cabañas JG, et al; Adult Basic and Advanced Life Support Writing Group. Part 3: adult basic and advanced life support: 2020 American Heart Association guidelines for cardiopulmonary resuscitation and emergency cardiovascular care. Circulation 2020; 142(16 Suppl 2):S366-468.

53. Berg KM, Soar J, Andersen LW, et al; Adult Advanced Life Support Collaborators. Adult advanced life support: 2020 international consensus on cardiopulmonary resuscitation and emergency cardiovascular care science with treatmen recommendations. Circulation 2020; 142(16 Suppl 1):S92-139.

54. Reynolds JC, Hartley T, Michiels EA, Quan L. Long-term survival after drowningrelated cardiac arrest. J Emerg Med 2019; 57:129-39.

55. Youn CS, Choi SP, Yim HW, Park KN. Out-of-hospital cardiac arrest due to drowning: an Utstein Style report of 10 years of experience from St. Mary's Hospital. Resuscitation 2009; 80:778-83.

56. Suominen P, Baillie C, Korpela R, et al. Impact of age, submersion time and water temperature on outcome in near-drowning. Resuscitation 2002 . 52:247-54

57. Szpilman D, Soares M. In-water resuscitation--is it worthwhile? Resuscitation $2004 \cdot 63 \cdot 25-31$.

58. Siebke H, Rod T, Breivik H, Link B. Survival after 40 minutes; submersion without cerebral sequelae. Lancet 1975; 1:1275-7.

59. Watson RS, Cummings P, Quan L, Bratton S, Weiss NS. Cervical spine injuries among submersion victims. J Trauma 2001; 51:658-62

60. Causey AL, Tilelli JA, Swanson ME. Predicting discharge in uncomplicated near-drowning. Am J Emerg Med 2000; 18:9-11.

61. Noonan L, Howrey R, Ginsburg CM. Freshwater submersion injuries in children: a retrospective review of seventy-five hospitalized patients. Pediatrics 1996; 98(3 Pt 1):368-71

62. Comess KA, DeRook FA, Russell ML, Tognazzi-Evans TA, Beach KW. The incidence of pulmonary embolism in unexplained sudden cardiac arrest with pulseless electrical activity. Am J Med 2000; 109:351-6.

63. Jaff MR, McMurtry MS, Archer SL, et al. Management of massive and submassive pulmonary embolism, iliofemoral deep vein thrombosis, and chronic thromboembolic pulmonary hypertension: a scientific statement from the American Heart Association. Circulation 2011; 123:1788-830.

64. Wood KE. Major pulmonary embolism: review of a pathophysiologic approach to the golden hour of hemodynamically significant pulmonary embolism. Chest 2002; 121:877-905

65. Javaudin F, Lascarrou JB, Le Bastard Q, et al. Thrombolysis during resuscitation for out-of-hospital cardiac arrest caused by pulmonary embolism increases 30day survival: findings from the French National Cardiac Arrest Registry. Chest 2019; 156:1167-75

66. Soar I, Maconochie I, Wyckoff $\mathrm{MH}$, et al. 2019 international consensus on cardiopulmonary resuscitation and emergency cardiovascular care science with treatment recommendations. Resuscitation 2019; 145:95-150.

67. Beckett VA, Knight M, Sharpe P. The CAPS Study: incidence, management and outcomes of cardiac arrest in pregnancy in the UK: a prospective, descriptive study. BJOG 2017; 124:1374-81.

68. Schaap TP, Overtoom E, van den Akker T, et al. Maternal cardiac arrest in the Netherlands: a nationwide surveillance study. Eur J Obstet Gynecol Reprod Biol 2019; 237:145-50.

69. Einav S, Kaufman N, Sela HY. Maternal cardiac arrest and perimortem caesarean delivery: evidence or expert-based? Resuscitation 2012; 83:1191-200

70. Benson MD, Padovano A, Bourjeily G, Zhou Y. Maternal collapse: challenging the four-minute rule. EBioMedicine 2016; 6:253-7.

71. Svinos H. Towards evidence based emergency medicine: best BETs from the Manchester Royal Infirmary. BET 1. Emergency caesarean section in cardiac arrest before the third trimester. Emerg Med J 2008; 25:764-5.

72. Biderman $P$, Carmi U, Setton E, et al. Maternal salvage with extracorporeal life support: lessons learned in a single center. Anesth Analg 2017; 125:1275-80.

73. Chauhan A, Musunuru H, Donnino M, et al. The use of therapeutic hypothermia after cardiac arrest in a pregnant patient. Ann Emerg Med 2012; 60:786-9. 


\section{(Code SMJ 202108B) \\ Question 1. Regarding the management of a patient presenting with torsades de pointes: \\ (a) Intravenous (IV) amiodarone $150 \mathrm{mg}$ bolus over 10-15 minutes can be given. \\ (b) IV lidocaine bolus $1-1.5 \mathrm{mg} / \mathrm{kg}$ can be given. \\ (c) Synchronised cardioversion at $200 \mathrm{~J}$ biphasic should be carried out. \\ (d) IV magnesium sulphate bolus over 10-15 minutes can be given.}

SINGAPORE MEDICAL COUNCIL CATEGORY 3B CME PROGRAMME

Question 2. In a patient with return of spontaneous circulation after cardiopulmonary resuscitation:

(a) Hypothermia therapy with target core temperature of $30^{\circ} \mathrm{C}-32^{\circ} \mathrm{C}$ for 48 hours will improve the patient's chance of survival with good functional recovery.

(b) Emergency coronary angiography should be arranged if the electrocardiogram (ECG) shows ST elevation myocardial infarction.

(c) Ventilation should be continued with $100 \%$ oxygen for the next 24 hours.

(d) IV dopamine $10 \mathrm{mcg} / \mathrm{kg} / \mathrm{min}$ should be started in a patient with mean arterial pressure $75 \mathrm{mmHg}$.

Question 3. A patient presented with exertional dyspnoea. His blood pressure (BP) was $98 / 62 \mathrm{mmHg}$, heart rate 160 beats per minute (bpm), oxygen saturation $\left(\mathrm{SaO}_{2}\right) 90 \%$ on room air and body temperature $36^{\circ} \mathrm{C}$. His ECG shows wide complex tachycardia, QRS duration of 160 ms with northwest axis. The next appropriate steps are:

(a) Synchronised cardioversion at $150 \mathrm{~J}$ biphasic should be carried out after adequate analgesia and sedation.

(b) IV amiodarone $150 \mathrm{mg}$ bolus over 10-15 minutes can be given.

(c) IV lidocaine bolus $1-1.5 \mathrm{mg} / \mathrm{kg}$ can be given.

(d) IV adenosine fast bolus can be given.

Question 4. A patient complained of feeling light-headed. Her ECG showed complete heart block with a ventricular rate of $30 \mathrm{bpm}$. Clinically, she was alert and her $\mathrm{BP}$ was $120 / 70 \mathrm{mmHg}$ and $\mathrm{SaO}_{2} 99 \%$ on room air. How can the patient be managed?

(a) IV atropine boluses of $0.6 \mathrm{mg}$ (up to a total of $2.4 \mathrm{mg}$ ) should be given.

(b) IV dopamine should be started at $5 \mathrm{mcg} / \mathrm{kg} / \mathrm{min}$ up to maximum of $20 \mathrm{mcg} / \mathrm{kg} / \mathrm{min}$, depending on her response.

(c) IV adrenaline infusion may be initiated at a rate of $2-10 \mathrm{mcg} / \mathrm{min}$ and increased gradually till the target heart rate is achieved.

(d) Continuous ECG monitoring should be initiated, with transcutaneous pacing on standby in case she deteriorates.

Question 5. The following statements are true:

(a) Routine cervical immobilisation for drowning victims should not be practised unless there is suspicion of cervical spine injury, as this would impede resuscitative efforts.

(b) Continuous left lateral displacement of the uterus should be performed during resuscitation of a woman with first-trimester pregnancy presenting with cardiac arrest.

(c) Extracorporeal membrane oxygenation may be considered in a patient presenting with cardiac arrest from acute pulmonary embolism.

(d) Empirical IV thrombolytics should not be administered to a patient presenting with cardiac arrest from suspected acute pulmonary embolism due to bleeding risks.

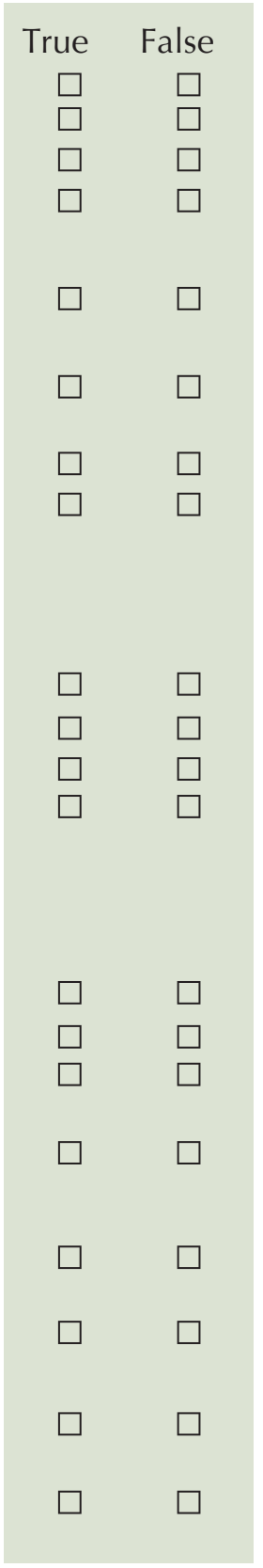

\section{Doctor's particulars:}

Name in full:

MCR no:

Specialty:

Email:

\footnotetext{
SUBMISSION INSTRUCTIONS:

Visit the SMJ website: http://www.smj.org.sg/current-issue and select the appropriate quiz. You will be redirected to the SMA login page.

For SMA member: (1) Log in with your username and password (if you do not know your password, please click on 'Forgot your password?'). (2) Select your answers for each quiz and click 'Submit'.

For non-SMA member: (1) Create an SMJ CME account, or log in with your SMJ CME username and password (for returning users). (2) Make payment of SGD 21.40 (inclusive of $7 \%$ GST) via PayPal to access this month's quizzes. (3) Select your answers for each quiz and click 'Submit'.

RESULTS:

(1) Answers will be published online in the SMJ October 2021 issue. (2) The MCR numbers of successful candidates will be posted online at the SMJ website by 29 October 2021. (3) Passing mark is $60 \%$. No mark will be deducted for incorrect answers. (4) The SMJ editorial office will submit the list of successful candidates to the Singapore Medical Council. (5) One CME point is awarded for successful candidates. (6) SMC credits CME points according to the month of publication of the CME article (i.e. points awarded for a quiz published in the August 2021 issue will be credited for the month of August 2021, even if the deadline is in October 2021).

Deadline for submission (August 2021 SMJ 3B CME programme): 12 noon, 22 October 2021.
} 